\title{
TRANSPORT AND INTERACTION OF DRUGS IN LEUKOCYTES
}

\author{
Michael J. Marks and Fedor MedzihradskY* \\ Department of Biological Chemistry and Upjohn Center for Clinical Pharmacology, \\ The University of Michigan Medical Center. Ann Arbor, Mich. 48104. U.S.A.
}

(Received 15 January 1974; accepted 1 March 1974)

\begin{abstract}
The accumulation of selected CNS drugs by rat leukocytes was previously reported. This paper presents evidence for the transport into leukocytes of additional drugs. Also studied was the inhibition of the latter processes by various structurally related compounds. The markedly rapid and sodium-independent uptakes into rat leukocytes of amphetamine, codeine, methadone and naloxone fulfilled the basic criteria for active transport. The uptake of morphine was apparently accomplished by more than one process. The affinities of the high capacity transport systems (approximate $V_{\max }: 100 \mathrm{nmoles} / \mathrm{g}$ cells $/ 5 \mathrm{sec}$ ) varied considerably as reflected by the two extreme $K_{m}$ values obtained for methadone (20 $\mu \mathrm{M})$ and morphine $(1.8 \mathrm{mM})$. A variety of amines inhibited the cellular transport of the drugs. Most potent inhibitors were quinacrine $\left(K_{i}: 0.5\right.$ to $\left.3 \mu \mathrm{M}\right)$. desipramine $\left(K_{i}: 6-20 \mu \mathrm{M}\right)$ and methadone $\left(K_{i}: 18-25 \mu \mathrm{M}\right)$. Morphine and tryptamine exhibited inhibition constants higher than $1 \mathrm{mM}$. The cellular transport processes newly described in rat leukocytes apparently represent a novel addition to the heterogenous biological transport of basic amines. The structural specificity of a mine transport in various tissues is discussed.
\end{abstract}

WITHIN the growing interest in the biological effects of drugs, numerous studies have been made on drug distribution and the interaction of drugs with cellular components. The biological transport of drugs received relatively little attention. Most of the available information referring to the latter processes focuses on the physiological transport of drugs, emphasizing the uptake of these compounds into various organs. ${ }^{1}$ A recent review of drug transport ${ }^{2}$ disclosed the lack of systematic investigations of the mechanisms by which drugs enter cells.

Within our study of cellular drug transport, we have previously described the active transport of benzomorphans in leukocytes, which were used as model mammalian cells. ${ }^{3,4}$ The presented data suggested that the transport process in leukocytes is different from the uptake system for various amines, described in the blood platelet. ${ }^{5-9}$ Recently we reported that, in addition to benzomorphans, leukocytes also accumulated methadone and morphine. ${ }^{10}$

The present paper provides evidence for the active transport in leukocytes of further CNS drugs. In addition to the characterization of the transport processes, the effects of various compounds on the cellular uptakes were investigated. The cellular transport of drugs in leukocytes is discussed in light of the hitherto described uptake processes for amines in various tissue.

* Send requests for reprints to: Dr. Fedor Medzihradsky, Department of Biological Chemistry, The University of Michigan Medical School, Ann Arbor, Mich. 48104, U.S.A. 


\section{EXPERIMENTAL PROCEDURES}

Materials. The drugs used in this study were kindly provided by Drs. H. H. Swain and J. H. Woods, Department of Pharmacology, University of Michigan. The radiolabeled compounds were purchased from Mallinckrodt Chemical Works, St. Louis, Mo., except ${ }^{3} \mathrm{H}$-pentazocine, which was a gift from the Winthrop Research Institute, Rensselaer, N.Y. Plasmagel, a modified gelatin solution used for the separation of leukocytes, was obtained from HTI Corp., Buffalo, N.Y. The biochemicals used in this study, e.g. ouabain, were purchased from Sigma Chemical Co., St. Louis, Mo. All other chemicals were of reagent grade.

Scparation of leukocytes. Blood was obtained from the vena cavae of lightly anesthetized (diethylether), male, Sprague-Dawley rats, weighing $300 \mathrm{~g}$. Leukocytes were separated by a previously developed procedure yielding blood cells with ascertained viability and morphological integrity. ${ }^{11}$ The separated leukocytes were obtained within $2 \mathrm{hr}$ after the collection of blood with an average yield of 59 per cent. This yield corresponded to $8.5 \times 10^{6} \mathrm{cells} / \mathrm{ml}$ of blood.

Conditions of incubation and quantitation of drug uptake. Throughout this study, an incubation medium was used containing the following final concentrations ( $\mathrm{mM}$ ): $\mathrm{NaCl}, 133 ; \mathrm{KCl}, 5 \cdot 3 ; \mathrm{MgSO}_{4}, 1 \cdot 3 ; \mathrm{Na}_{2} \mathrm{HPO}_{4}, 13 \cdot 3 ;$ and glucose, 10 . The $\mathrm{pH}$ of the medium was adjusted to 7.4 with $\mathrm{HCl}$. After the isolation, the leukocytes were suspended with the above medium to yield a concentration of approximately $10^{7}$ cells/ $\mathrm{ml}$. Prior to the addition of drugs, this cellular suspension was routinely incubated for $1 \mathrm{hr}$ at $37^{\circ}$. To $1 \mathrm{ml}$ of the preincubated leukocyte suspension was rapidly added $1 \mathrm{ml}$ of incubation medium containing either the drug, the cellular uptake of which was investigated, or both the transported drug and the compound used as potential inhibitor. The amount of the drugs in the added aliquot corresponded to twice the desired final concentration during the incubation. The added solution also contained $0.1 \mu \mathrm{Ci}$ of the transported radiolabeled drug. The incubation was carried out at $37^{\circ}$ for the times indicated. Due to the rapid cellular uptakes, the linear ranges of drug transport necessitated the termination of the incubation between 5 and $60 \mathrm{sec}$ after the addition of the particular drug.

The incubated cell suspension was quickly filtered through glass-fiber filters supported on a Millipore assembly. The filters were previously thoroughly washed with $0.9 \% \mathrm{NaCl}$ by repeated suspension and decantation. In order to reduce the extent of nonspecific binding of radioactive compounds, the pretreated filters were finally washed in $0.9 \% \mathrm{NaCl}$ saturated with $\mathrm{N}$-amyl alcohol. The cells on the filter were rapidly washed three times with $6 \mathrm{ml}$ each of ice-cold $0.9 \% \mathrm{NaCl}$. The filters were then placed in standard glass scintillation vials and covered with $0.3 \mathrm{ml}$ of Protosol. The vials were capped and incubated at $55^{\circ}$ for $2 \mathrm{hr}$ in order to complete digestion of the biological material. After the vials were cooled to room temperature, $10 \mathrm{ml}$ of a scintillation medium (5 PPO and $0 \cdot 3 \mathrm{~g}$ dimethyl-POPOP/1. of toluene*) was added. The radioactivity was measured in a scintillation spectrometer, Packard, model 3320. The average counting efficiencies for ${ }^{3} \mathrm{H}$ - and ${ }^{14} \mathrm{C}$-labeled compounds were 45 and 80 per cent, respectively, as determined by the method of internal standardization. Appropriate blanks were run through the whole procedure. Even in experiments in which low uptakes were observed, the blanks did not exceed 50 per cent of the measured net counts.

* PPO $=$ 2,5-diphenyloxazole $;$ POPOP $=1$,4-bis-2-(5-phenyloxazolyl)-benzene. 
In control experiments, carried out to establish binding of drug to cellular material, the above described incubations were performed using leukocytes previously freeze-thawed or heated. Suspensions of leukocytes in the standard incubation medium were frozen by immersion in a mixture of dry ice and acetone at $-70^{\circ}$ and then thawed at room temperature. After repeating the freeze-thaw step, the cells were kept at $37^{\circ}$. In other experiments, suspensions of cells were heated at $80^{\circ}$ for $7 \mathrm{~min}$ and subsequently kept at $37^{\circ}$. After the above described treatments, the uptake of radiolabeled pentazocine was determined.

In experiments carried out to investigate the effect of temperature on the transport process, the cellular uptake of drug was determined at $0^{\circ}, 18^{\circ}$ and $36^{\circ}$. Leukocytes, suspended in the standard incubation medium, were incubated for $60 \mathrm{~min}$ at the indicated temperatures. Subsequently, radiolabeled drug was added and the cellular uptake determined.

Expression of results. The rate of cellular uptake was expressed as moles of drug accumulated/g of leukocytes and time. One $\mathrm{g}$ leukocytes, packed by centrifugation, corresponded to an average cell count of $10^{9}$ and to $67 \mathrm{mg}$ protein respectively. ${ }^{11}$ The results are presented as mean values \pm the standard deviation. The inhibition constants $\left(K_{i}\right)$ were calculated from the appropriate intercepts in the LineweaverBurk plots of the uptake in the presence and absence of inhibitor. In addition, $K_{i}$ values were estimated graphically according to the method of Dixon. ${ }^{12}$

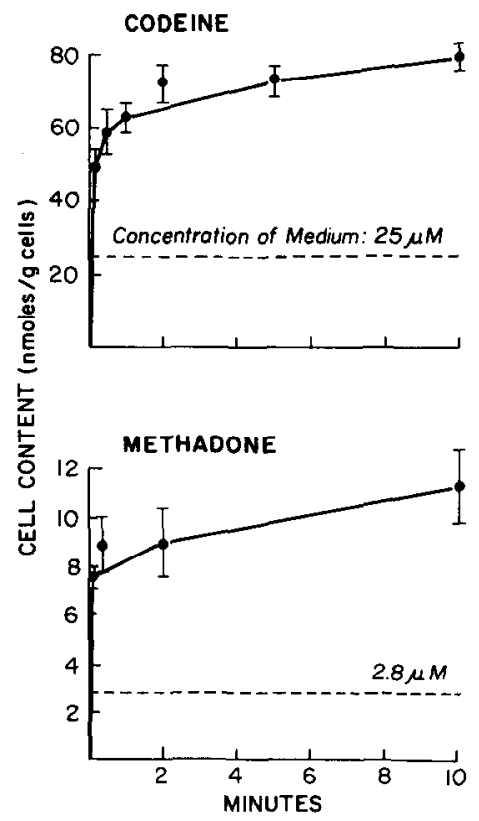

FiG. 1. Time course of the uptakes of codeine and methadone by rat leukocytes. Suspensions of cells were incubated at $37^{\circ}$ for the various times indicated, using the medium ( $\mathrm{pH} \mathrm{7.4)} \mathrm{described} \mathrm{in} \mathrm{the} \mathrm{text.} \mathrm{The}$ initial concentration of the drug in the incubation medium is shown in the figure by the dotted lines. The conditions for the determination of cellular uptake, by quantitating the radiolabeled drug, were as described in Methods. One g leukocytes corresponded to approximately $10^{\circ}$ cells. Plotted are mean values \pm S.D. of at least four separate experiments in which different preparations of leukocytes were used. 


\section{RESULTS}

Characterization of leukocytes. Yield and purity of the cells as well as their morphological integrity and viability were ascertained in an earlier study. ${ }^{11}$ Crosscontamination by other blood cells of the leukocyte preparation was less than 3 per cent. In addition to thorough microscopic examination of the stained cellular preparations, the investigated parameters of viability were: trypan blue exclusion, determination of the cellular contents of $\mathrm{K}^{+}, \mathrm{Na}^{+}$and adenosine triphosphate, and measurements of oxygen consumption. These criteria of cellular viability were fulfilled over an incubation period at $37^{\circ}$ of $3-4 \mathrm{hr}$ after the isolation. ${ }^{11}$

Time-dependent uptake of drugs. The transport of drugs into leukocytes was characterized by a markedly rapid rate of uptake (Figs. 1-3). Due to the fast transport. the linear ranges of drug uptake were limited to a narrow time interval. All the investigated drugs, when present at a concentration below their corresponding $K_{m}$ valuc (Table 1), were accumulated in leukocytes. The extent of cellular accumulation at saturation depended on the external concentration and was 4-fold at low contents of the particular drug in the medium. Accumulation of morphine, however, was obtained only at a concentration in the medium of less than one-third of its $K_{m}$ value (Fig. 3).

Uptake by disrupted cells. Both heat treatment and freezing of leukocytes strongly reduced the cellular uptake of drugs. The data in Table 2 show a decrease of 85 per cent in the accumulation of pentazocine in previously treated leukocytes as compared to control cells. An exception in this relation was observed with morphine, the incubation of which with heat-treated leukocytes resulted in increased radioactivity

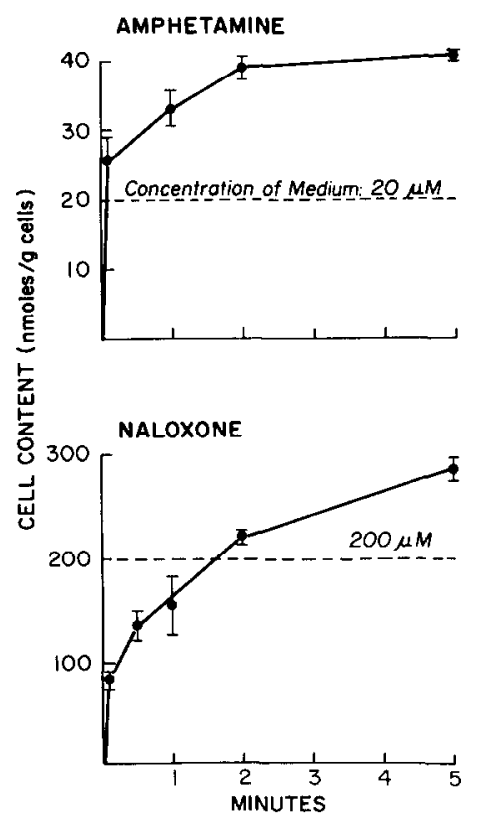

FIG. 2. Time course of the uptakes of amphetamine and naloxone by rat leukocytes. (See also legend to Fig. 1.) 


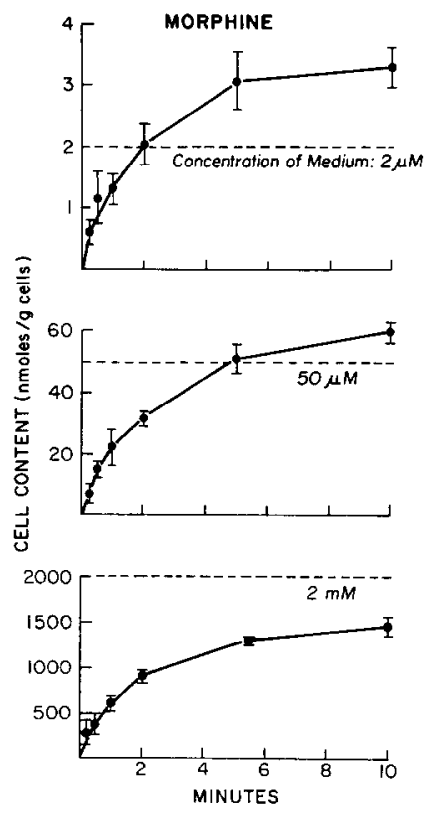

FIG. 3. Time course of the uptake of morphine by rat leukocytes. Suspensions of cells were incubated at $37^{\circ}$ for the various times indicated. using the medium (pI 7.4) described in the text. The cellular uptake of morphine was investigated at three different external concentrations of the drug. The initial concentration of morphine in the incubation medium is shown in the figure by the dotted lines. (See also legend to Fig. 1.)

Table 1. Characterization of DRUg tRanSPORT IN LELKOCYTES*

\begin{tabular}{lccccc}
\hline & & & \multicolumn{3}{c}{ Inhibition of transport $(\%)$} \\
Transported drug & $\begin{array}{c}\text { Apparent } K_{m} \\
(\mu \mathrm{M})\end{array}$ & $\begin{array}{c}\text { Apparent } V_{\text {max }} \\
\text { (nmoles } / \mathrm{g} \text { cells } \times \text { time) }\end{array}$ & $\begin{array}{c}\text { NaF } \\
(30 \mathrm{mM})\end{array}$ & $(1 \mathrm{mM})$ & 0 \\
\hline Amphetamine & 90 & $100(5 \mathrm{sec})$ & 59 & 0 & 93 \\
Codeine & 200 & $140(5 \mathrm{sec})$ & 59 & 9 & 88 \\
Methadone & 20 & $115(5 \mathrm{sec})$ & 50 & 10 & 80 \\
Morphine & 1800 & $1200(60 \mathrm{sec})$ & 19 & 4 & 89 \\
Naloxone & 180 & $210(30 \mathrm{sec})$ & 55 & 0 & 80 \\
Pentazocine & 40 & $100(5 \mathrm{sec})$ & 57 & 3 & 85 \\
\hline
\end{tabular}

* The listed kinctic constants of drug uptake were obtained in the experiments shown in Figs. 4-6. In investigating the inhibition of drug transport, rat leukocytes were preincubated with the inhibitors at $37^{\circ}$ for $60 \mathrm{~min}$ in the medium described in the text. In other experiments, suspensions of cells were kept for $60 \mathrm{~min}$ at $0^{\circ}$. After these treatments. a solution of the investigated drug in the incubation medium was added. The final concentrations of the drugs were lower than their respective $K_{m}$ values. The conditions for the determination of cellular drug uptake were as described in Methods. The numbers listed represent mean values of at least four separate experiments in which different preparations of leukocytes were used.

of the cellular material. However, the latter effect was not observed when frozenthawed leukocytes were used.

Kinetic parameters of drug transport. The Lineweaver-Burk plots of the uptakes are shown in Figs. 4-6. The numerical values for the apparent $K_{m}$ and $\boldsymbol{V}_{\max }$ are summarized in Table 1. In these experiments drug uptake had to be determined at 


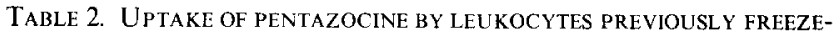
THAWED OR HEATED*

\begin{tabular}{lc}
\hline $\begin{array}{c}\text { Treatment of } \\
\text { cells }\end{array}$ & $\begin{array}{c}\text { Rate of pentazocine } \\
\text { uptake } \\
\text { (nmoles/g cells } \times 5 \mathrm{sec} \text { ) }\end{array}$ \\
\hline Control & $12 \cdot 7 \pm 2.9$ \\
Frozen-thawed & $1.8 \pm 1.0$ \\
Heated & $1.9 \pm 1.0$ \\
\hline
\end{tabular}

* Control cells were maintained at $37^{\circ}$ at all times. The treatment of other leukocytes and the determination of the uptake of radiolabeled pentazocine were as described in Methods. The concentration of pentazocine in the incubation medium was in all cases $10 \mu \mathrm{M}$. Presented are mean values $\pm S$.D. of four separate experiments in which different preparations of leukocytes were used.

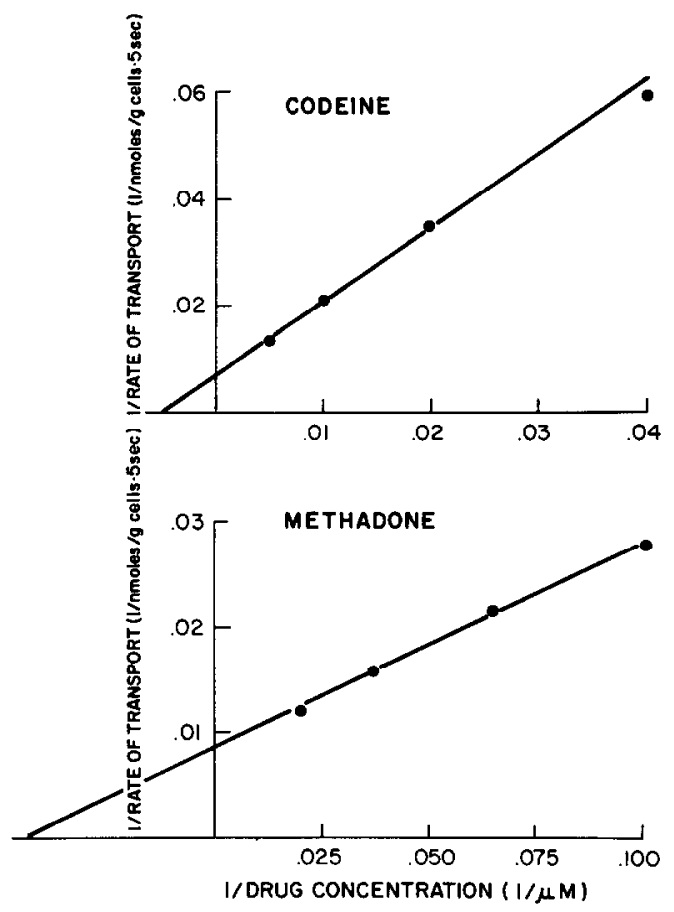

FIG. 4. Lineweaver-Burk plots of the uptake of codeine and methadone by rat leukocytes. Plotted are the reciprocal initial concentrations of the drugs in the medium against the corresponding reciprocal cell contents at the times indicated. The obtained values for $K_{m}$ and $V_{\max }$ are listed in Table 1 . The conditions of drug quantitation were as described in Methods. Presented are mean values of at least four separate experiments in which different preparations of leukocytes were used.

various times in order to investigate the linear range of the transport process. On the basis of their apparent $K_{m}$ values, the transported drugs can be divided into three groups. In order of decreasing affinity these groups are: methadone and pentazocine; amphetamine; naloxone and codeine; morphine. A less pronounced differentiation among the drugs was obtained by comparing their rates of transport. Except for naloxone, the apparent $V_{\max }$ values of the other drugs were similar, ranging from 100 


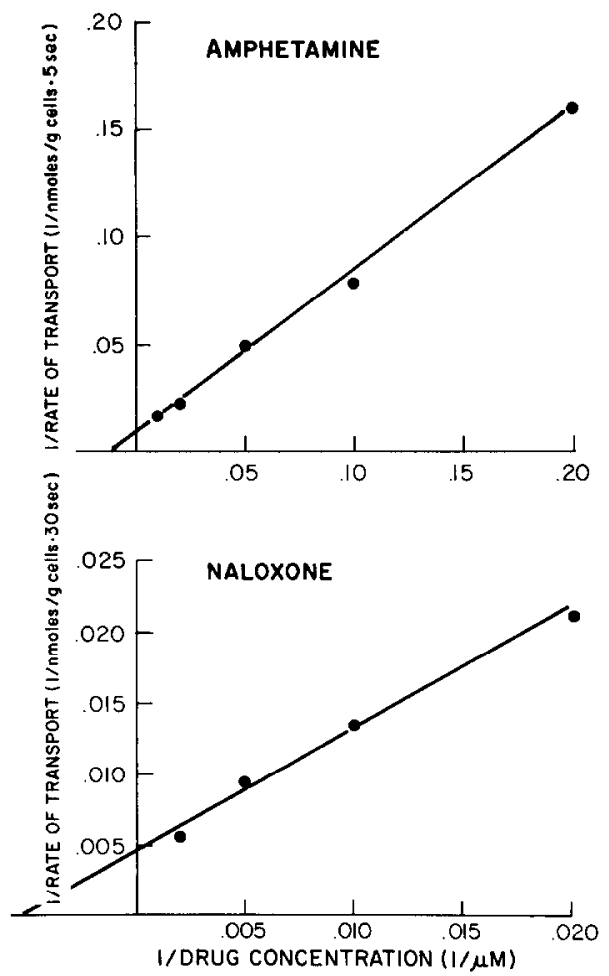

FIG. 5. Lineweaver-Burk plots of the uptake of amphetamine and naloxone by rat leukocytes. (See also legend to Fig. 4.)

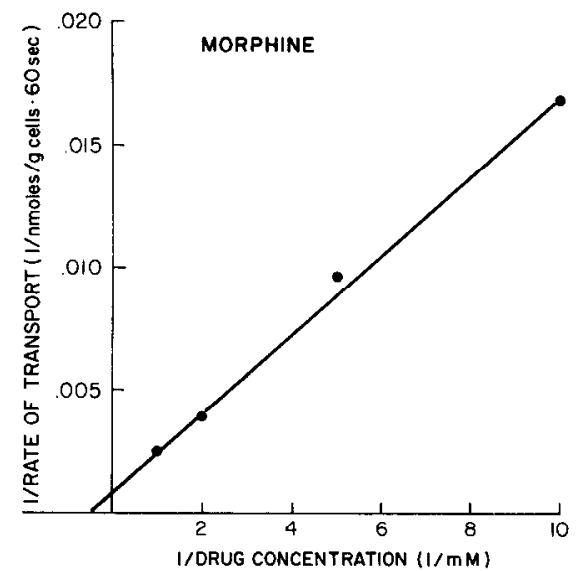

FIG. 6. Lineweaver-Burk plot of the uptake of morphine by rat leukocytes. Plotted are the reciprocal initial concentrations of the drug in the medium against the reciprocal cell content at the times indicated. (See also legend to Fig. 4.)

to $140 \mathrm{nmoles} / \mathrm{g}$ cells $/ 5 \mathrm{sec}$. Naloxone was transported into leukocytes with a $V_{\max }$ of $35 \mathrm{nmoles} / \mathrm{g} / 5 \mathrm{sec}$.

Characterization of the uptake process. In the presence of sodium fluoride, the uptake of most drugs decreased by 50-60 per cent as compared to the controls (Table 
1). Again, the exception was morphine, the transport of which was affected only 19 per cent. Ouabain had little or no effect on the transport of the investigated drugs and the uptake of all the drugs was strongly reduced at $0^{\circ}$. The Arrhenius plot, i.e. $\log V_{\max }$ plotted against $1 / \mathrm{T}\left({ }^{\circ} \mathrm{K}\right)$, generated for the temperature dependence of the uptake of pentazocine, was linear with temperature in the range from $0^{\circ}$ to $36^{\circ}$ (Fig. 7). The $Q_{10}$ for the $V_{\max }$ was calculated to be $2 \cdot 05$.

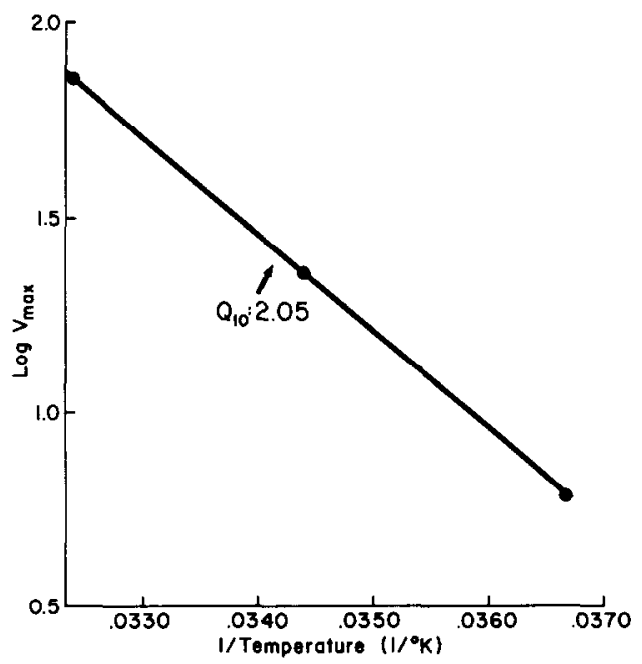

FiG. 7. Arrhenius plot of $V_{\max }$ values for the uptake of pentazocine. The slope of the line corresponds to a $Q_{10}$ of 2.05. The experimental conditions were as described in Methods. Presented are mean values obtained from three separate experiments.

The effects of temperature and of metabolic inhibitors on the cell count and on the viability of leukocytes were determined (Table 3). Relative to the controls, none of the investigated conditions caused changes in either the total cell count or the per cent of leukocytes stained by trypan blue.

TABLE 3. EFFECT OF TEMPERATURE AND OF METABOLIC INHIBITORS ON CELL COUNT AND VIABILITY OF LELKOCYTES*

\begin{tabular}{ccc}
\hline $\begin{array}{c}\text { Treatment of } \\
\text { cells }\end{array}$ & $\begin{array}{c}\text { Cell count } \\
(\text { cells } / \mathrm{ml})\end{array}$ & $\begin{array}{c}\text { Uptake of trypan } \\
\text { blue } \\
\text { (\% stained cells })\end{array}$ \\
\hline 9 & $1.08 \times 10^{7}$ & $<3$ \\
$22^{\circ}$ & $1.07 \times 10^{7}$ & $<3$ \\
36 & $1.06 \times 10^{7}$ & $<3$ \\
Control & $8.6 \times 10^{6}$ & $<3$ \\
$3 \mathrm{mM}$ Iodoacetamide & $9.0 \times 10^{6}$ & $<3$ \\
Control & $9.6 \times 10^{6}$ & $<3$ \\
$3 \mathrm{mM} \mathrm{NaF}$ & $9.2 \times 10^{6}$ & $<3$ \\
$6 \mathrm{mM} \mathrm{NaF}$ & $9.3 \times 10^{6}$ & $<3$ \\
\hline
\end{tabular}

* Suspensions of leukocytes were exposed to the indicated conditions for $60 \mathrm{~min}$. Control cells were suspended in the standard incubation medium and kept at $37^{\circ}$. Incubations with inhibitors were carried out at $37^{\circ}$. Aliquots of the control and of treated cellular suspensions were incubated with $0.15 \%$ trypan blue for 15 min at $37^{\circ}$. Presented are the results of a typical experiment. 
TABLI: 4. INHIBITION OF DRUG TRANSPORT IN LEUKOCYTES BY VARIOUS COMPOLNIDS*

\begin{tabular}{|c|c|c|c|c|c|c|}
\hline $\begin{array}{l}K i \text { values } \\
\text { of } \\
\text { inhibitors }\end{array}$ & $\begin{array}{l}\text { Amphetamine } \\
\text { (10) }\end{array}$ & $\begin{array}{l}\text { Codeine } \\
(50)\end{array}$ & $\begin{array}{l}\text { Methadone } \\
\text { (10) }\end{array}$ & $\begin{array}{l}\text { Morphine } \\
(200)\end{array}$ & $\begin{array}{l}\text { Naloxone } \\
\quad(50)\end{array}$ & $\begin{array}{l}\text { Pentazocine } \\
\text { (10) }\end{array}$ \\
\hline Amphetamine & & 85 & 110 & $>1000$ & 75 & 100 \\
\hline Cocaine & 160 & 150 & 120 & $>1000$ & 125 & 100 \\
\hline Codeine & 200 & & 200 & $>1000$ & 160 & 220 \\
\hline Desipramine & 6 & 20 & 8 & $>1000$ & 15 & 8 \\
\hline Levallorphan & 45 & 65 & 60 & $>1000$ & 45 & 40 \\
\hline Levorphanol & 130 & 170 & 130 & & 60 & 140 \\
\hline Methadone & 18 & 25 & & 400 & 25 & 22 \\
\hline Morphine & $>1000$ & $>1000$ & $>1000$ & & $>1000$ & $>1000$ \\
\hline Nalorphine & 230 & 350 & 200 & & 90 & 355 \\
\hline Naloxone & 150 & 250 & 250 & $>1000$ & & 200 \\
\hline Pentazocine & 30 & 100 & 40 & $>1000$ & 40 & \\
\hline Quinacrine & 2 & 2 & 2.5 & 10 & $0 \cdot 5$ & 3 \\
\hline Thebaine & 35 & 65 & 40 & 200 & 25 & 45 \\
\hline Tryptamine & $>1000$ & $>1000$ & $>1000$ & & $>1000$ & $>1000$ \\
\hline
\end{tabular}

* In addition to the data on the inhibition, the initial concentrations of the transported drugs in the incubation medium are listed. The inhibitor was added to suspensions of leukocytes simultaneously with the transported drug. Further conditions of the experiments were as described in Methods. The $K_{i}$ values were calculated from the corresponding intercepts in Lineweaver-Burk plots of the uptake in the presence and absence of inhibitor. The inhibition constants were also estimated graphically from corresponding Dixon plots of the data. Presented are mean values of at least four separate experiments in which different preparations of leukocytes were used.

Inhibition of cellular drug transport. The described transport processes were competitively inhibited by a variety of compounds. According to their decreasing potencies as inhibitors, the compounds in Table 4 can be divided into the following groups: quinacrine, desipramine and methadone; thebaine, pentazocine and levallorphan; amphetamine and cocaine; codeine, naloxone and nalorphine; morphine and tryptamine. Quinacrine proved to be a markedly potent inhibitor of all the investigated processes including the uptake of morphine. The latter process, however, was not particularly affected by desipramine, an otherwise strong inhibitor of cellular drug transport in leukocytes. Whereas the inhibition constants for the various compounds ranged from 0.5 to $350 \mu \mathrm{M}$, in inhibiting the uptake of morphine only quinacrine, desipramine and thebaine exhibited $K_{i}$ values in the submillimolar range.

\section{DISCUSSION}

There is a lack of information concerning processes by which drugs enter cells. In view of the possible role of cellular transport in the overall biologic action of drugs, the investigation of the latter processes in human cellular preparations becomes of great interest. The convenient availability of blood cells in general and the morphological characteristics of leukocytes in particular led us to investigate the processes by which drugs cross the plasma membrane of these model mammalian cells.

Our first results indicated that pentazocine. a potent analgesic widely used clinically, is transported into leukocytes by a process that fulfilled all the basic criteria 
for active transport. ${ }^{3}$ Furthermore, the markedly rapid cellular uptake of pentazocine correlated well with the fast onset of analgetic action of this drug and its rapid entry into the brain after intraperitoneal administration to rats. ${ }^{13}$ In addition to pentazocine, other CNS drugs were also found to be actively transported into leukocytes. $^{10}$

A comparison of the characteristics of the transport processes in leukocytes with those described for the accumulation of various organic bases in platclets ${ }^{5-9}$ suggests a different mechanism for the phenomena observed in leukocytes. Whereas the uptakes by platelets were strongly inhibited by ouabain, suggesting a role of monovalent cations, this cardiac glycoside had little or no effect on the drug transport in leukocytes (Table 1). Additional characterization of the described uptakes of CNS drugs showed that these compounds were accumulated in leukocytes against their concentration gradient by a saturable process which was strongly affected by temperature and sodium fluoride. The latter finding is in agreement with the results of previous work in which the effects of additional metabolic inhibitors were investigated. ${ }^{3,10}$ The marked effects of temperature and metabolic inhibitors were further substantiated by the proven viability of the cells exposed to these conditions (Table 3). The expression of cellular drug concentration on the basis of cell water, amounting in leukocytes to 79 per cent, ${ }^{14,15}$ would increase the apparent accumulation ratio of the drugs in these cells. Evidence for the presence intracellularly of the transported drug in its unaltered form was obtained by the similarity of results of experiments in which the cellular drug content was determined by both gas--liquid chromatography and radioactive measurements. ${ }^{3.10}$

The described uptakes apparently required an intact plasma membrane: transport into leukocytes was strongly reduced after repeated freezing and thawing and after previous heating of the cells (Table 2). Additional evidence against protein binding as the underlying mechanism of drug accumulation was provided by the following data: inhibition of the uptake by metabolic inhibitors (Table 1), effect of temperature resulting in a $Q_{10}$ of 2 (Fig. 7) and dependence of the uptake on the presence of glucose in the incubation medium. ${ }^{3}$ These results, together with the saturability of the cellular accumulation and the competitive inhibition by chemical analogs, strongly suggest the presence in the leukocyte membrane of an active transport process for the investigated compounds. A direct relationship between the uptake of drugs into leukocytes and the cellular concentration of adenosine triphosphate was recently established. ${ }^{16}$ Whether the transported unaltered drug is bound intracellularly can not be directly resolved at this time. However, the markedly rapid efflux observed for pentazocine provides evidence against a tight intracellular binding of the drug. ${ }^{16}$

The uptake of morphine was characterized by exceptions. In addition to its distinctly low affinity for morphine (Table 1), the transport process was only weakly affected by sodium fluoride. The latter finding suggests that the uptake of morphine, as opposed to that of the other investigated drugs, is only partly based on active transport requiring metabolic energy. After carotid injection of the drugs, markedly higher uptake into brain of codeine and methadone relative to morphine was recently reported. ${ }^{17}$

The variety of compounds exhibiting competitive inhibition of the uptake into leukocytes of CNS drugs (Table 4) raises the question about the structural requirement of the transport process. The common structural property of all the compounds 
investigated in this study was their amine character. All but one of them represented substituted basic amines with the latter group removed from an aromatic residue by 34 carbon atoms. An exception was amphetamine, which as a primary amine competitively inhibited the cellular drug transport. On the other hand, tryptamine had little effect on the investigated uptake processes. Substitution in the aromatic ring showed no definite correlation with the affinity of the particular compound in the transport and/or with its potency as inhibitor. However, methylation of the phenolic hydroxyl group considerably decreased the respective $K_{i}$ value, as was seen in the series, morphine, codeine and thebaine.

There is considerable evidence for the accumulation of various amines in different tissues. Particularly well investigated is the uptake of these compounds by various preparations from brain ${ }^{18}$ and by blood platelets. ${ }^{5-9}$ The uptake of biogenic amines in preparations from brain was apparently highly sodium dependent and selectively affected by specific drugs; e.g., in brain slices and synaptosomes, desipramine strongly inhibited norepinephrine uptake, affected to a lesser degree the transport of serotonin, and had no effect on dopamine uptake. ${ }^{18,19}$ The heterogeneity of amine transport was underlined by a detailed study on the structural specificity of noradrenaline uptake by cardiac tissue, in which the inhibitory potencies of 43 drugs were investigated. ${ }^{20}$ The results of that study are in considerable contrast to our findings in leukocytes: the optimal chemical structure for an inhibitor seemed to be a primary amine and the aromatic ring was not an essential structural feature. Phenolic hydroxyl groups increased the effect, whereas $O$-methylation led to a striking decrease in inhibitory potency of a compound.

A common characteristic of the processes by which various organic bases were accumulated by blood platelets was their dependency on sodium. Ouabain, in addition to metabolic inhibitors, strongly inhibited the uptake of these compounds. ${ }^{5-9}$

The 2- to 3-fold accumulation of methyl-glyoxal-bis-guanylhydrazone in normal and leukemic leukocytes was reported earlier. ${ }^{21,22}$ The uptake derived its energy requirement from glycolysis and was inhibited 20 per cent by ouabain. The reported $K_{m}$ values ranged from 50 to $200 \mu \mathrm{M}$. The $V_{\max }$ of about $12 \mathrm{nmolcs} / \mathrm{min} / 2 \times 10^{8}$ cells was approximately 100 times slower than the rates observed in the present study. In addition, the structural requirements of the transport process were quite different: the presence in the transported molecule of at least two amine groups separated by four or more intervening atoms was required. Monoamines were ineffective.

The 3- to 4-fold accumulation of ${ }^{14} \mathrm{C}$-benzylamine in Ehrlich cells was reported to be the result of a rapid saturable as well as nonsaturable uptake process. ${ }^{23}$ The saturable process showed characteristics different from those of the amino acid transport system in these cells and was sodium independent. The affinity of the system for benzylamine was moderate, exhibiting a $K_{m}$ of $0.3 \mathrm{mM}$.

On the basis of their characteristics, the uptake processes described in this paper for the transport into leukocytes of various pharmacologically active amines are apparently different from most of the hitherto described transport systems for these compounds. Although the overall characteristics of the process, described in Ehrlich cells, for the uptake of benzylamine are quite similar to those describing the drug transport in leukocytes, further work is needed to establish the relationship of these processes. Results of on-going studies in this laboratory on drug transport in cellular preparations from nervous tissues should also aid in evaluating the biologic role of 
the processes existing in leukocytes. In connection with the latter aspect, the considerable capacity of the transport systems in leukocytes is of interest. In rat leukocytes this capacity calculates to approximately $1.2 \mathrm{~m}-\mathrm{moles} / \mathrm{min} / \mathrm{kg}$ of cells. On the hasis of this figure, it can be calculated that about $20 \mathrm{mg}$ of one of these drugs, assuming a molecular weight of 300 , can be transported per min into the leukocytes of a person with an average weight. The existence of the described transport processes in human leukocytes was established.*

Acknowledgements - This work was supported in part by United States Public Health Service Grants 2P11 GM15559 and R01-DA-00254

\section{REFERENCES}

1. L. S. Schanker, in Advances in Drug Research (Eds. N. J. Harper and A. B. Simmonds). Vol. 1, p. 71. Academic Press, New York (1964).

2. L. S. Schanker, in Metabolic Transport (Ed. L. E. Hokin), p. 543. Academic Press, New York (1972).

3. F. Medzinradsky, M. J. Marks and E. A. Carr, JR., Biochem. Pharmac. 21, 1625 (1972).

4. M. J. Marks and F. Mrdzimradsky, Fifth Int. Congr. Pharmac. San Francisco, abstr. 891 (1972).

5. H. M. SOLOMON and P. D. ZiEve, J. Pharmac. exp. Ther. 55, 112 (1967).

6. H. M. Solomon, C. Ashley, N. M. Spirt and W. B. Abrams. Clin. Pharmac. Ther. 10, $229(1969)$.

7. W. B. Abrams, Fedn Proc. 28, 544 (1969).

8. R. Pocelinko and H. M. Solomon, Biochem. Pharmac. 19, 697 (1970).

9. H. M. Solomon. N. M. SPIRT and W. B. Abrams, Clin. Pharmac. Ther. 11, 838 (1970).

10. F. Midzihradsky, M. J. Marks and J. I. MercalfF, Adv. Biochem. Psychopharmac. 8, 537 (1973).

11. F. Medzihradsky, M. J. Marks and J. I. Metcalfe, Biochem. Med. in press.

12. M. Dixon and E. C. Weis, The Enzymes, 2nd edn p. 327. Academic Press, New York (1964).

13. F. Medzinradsky and K. Ahmad, Life Sci. 10, 711 (1971).

14. D. L. Wilsov, Am. J. Physiol. 190, 104 (1957).

15. D. N. Baron and Ph. M. Robrirts. J. Physiol., Lond. 165, 219 (1963).

16. M. J. Marks and F. Medzihradsky, Mol Pharmac. in press.

17. W. H. Olbendorf. S. Hyman, L. Braun and S. Z. Oldendorf, Science, N.Y. 178, 984 (1972).

18. D. L. Murphy and I. J. Kopin, in Metabolic Transport (Ed. L. E. Hokin), p. 504. Academic Press, New York (1972).

19. A. Carlsson, K. Fuxi, B. Hamberger and M. Lindquist, Acta plysiol. scand. 67, 481 (1966).

20. L. L. IVershi, J. Pham. Pharmac. 16, 435 (1964).

21. M. Field, J. B. Block, V. T. Oliver IO and D. P. Rall, Cancer Res. 24, 1939 (1964).

22. J. B. BLock, M. FitLd and V. T. Oliverio, Cancer Res. 24, 1947 (1964).

23. H. N. CHRISTENSEN and M. LIA NG, J. blol. Chem. 241, 5552 (1966).

* Unpublished data. 